\title{
Effects of self-help groups intervention on coping strategies of parents of children with Autism Spectrum Disorder (ASD)
}

\author{
Ridhoyanti Hidayah, Retno Lestari \\ Study Program of Nursing Science, Faculty of Medicine, University of Brawijaya, Indonesia
}

\begin{tabular}{l}
\hline \hline Article Info \\
\hline Article history: \\
Received Dec 08, 2018 \\
Revised Jan 11, 2019 \\
Accepted Feb 15, 2019 \\
\hline
\end{tabular}

\section{Keywords:}

Autism spectrum disorder

Coping strategies

Parents

Self-help groups

\begin{abstract}
Coping strategies were significant predictors of psychosocial adaptation in parents of children with autism spectrum disorder (ASD). Self-help groups could be effective resources for parents in dealing with problems while caring for children with ASD. The purpose of this study was to analyze the effects of self-help groups on coping strategies in parents of children with ASD. This study used pre and post Quasi-experimental tests without a control group using self-help group interventions. There were thirty-three participants taken from the Malang City Autism Service Center using purposive sampling. Coping strategies based on cognitive and psychomotor abilities were measured using a questionnaire. The results showed Paired T-test in all groups, at 5\% significance level, statistically significant difference between mean score before and after self-help group interventions. Coping strategies in groups that received two supervised sessions and four times independently reached higher score compared to other groups. It can be concluded that it is important to implement self-help groups for parents who care for children with special needs.
\end{abstract}

Copyright $\odot 2019$ Institute of Advanced Engineering and Science. All rights reserved.

\section{Corresponding Author:}

Ridhoyanti Hidayah,

Study Program of Nursing Science, Faculty of Medicine,

University of Brawijaya, Ketawanggede, Malang, Indonesia.

Email: ridhoyantih@yahoo.com

\section{INTRODUCTION}

Autism spectrum disorder (ASD) is a neurological and developmental disorder that has a wide range of symptoms such as difficulties and delay in social interaction, communication and repetitive behaviors [1-3]. These deficits can be a major source of stress and frustration for parents when they raise children with ASD. The number of children diagnosed with ASD worldwide has and is still growing to 1 in 59 children in 2018 from 1 in 68 two years previous [4]. The Indonesian Autism Foundation reported an increase in the prevalence of ASD at 1 in 500 children in 2010, approximately 112,000 children with ASD within age of 5-19 years. The increase in cases of ASD also occurred in the city of Malang, reaching 847,175 children [5].

Previous study showed that parents with ASD children had destructive coping strategies instead of constructive coping strategies. These happened because parents had never received information about self-help groups to strengthening their coping strategies. Parents felt that the supporting group in the community was too formal so they felt difficulties to express feelings and share experiences [6]. Several factors which related to parents with ASD children stress were nature of situation, individual characteristics, environment, resources, perceive stress and coping responses. Therefore, it is important to build strong bonds between parents-facilitators in order to help parents of children with ASD to improve their coping skills, reduce their stress and enhance their quality of life. In addition, parents could boost their self-confidence and self-efficacy [7-9]. 
Self-help groups approach aimed to bringing together parents to identify their needs and gain resources to promote positive coping skills. A self-help group is a group where each member shares problems both physically and emotionally on certain issues. This group is a self-administered intervention which was designed for specific purpose. Self-help groups aim to develop empathy among fellow group members so that they provide mutual reinforcement to form new adaptive coping skills. Within the groups, it could also increase their autism awareness and facilitate access to services for ASD children. Groups can also practice to identify strengths and weaknesses in their social exchange information. Self-help groups with facilitators can help empower parents to obtain the information with regards to raising ASD children they need [10-12]. Self-help groups among parents with ASD children need to be implemented to help them deal with problems that are solved together in groups. The purpose of this study was to analyze the effects of self-help groups on coping strategies of parents of children with ASD.

\section{RESEARCH METHOD}

The design used in this study is Quasi experimental pre-post test without control group with self-help group interventions. The study was conducted to determine cognitive and psychomotor changes in parents with ASD children before and after having self-help group interventions. This study compared the changes of cognitive and psychomotor score within three groups as seen in research design can be seen in Table 1 .

Table 1. Research design

\begin{tabular}{lccc}
\hline \multicolumn{1}{c}{ Group } & Pre-Test & Treatment & Post-Test \\
\hline Group I & T1 & X1 & T2 \\
Group II & T1 & X2 & T2 \\
Group III & T1 & X3 & T2 \\
\hline
\end{tabular}

Information:

$\mathrm{T} 1=$ pre test

$\mathrm{T} 2=$ post test

$\mathrm{X} 1=$ experimental group using 6 sessions: 4 sessions with supervision, 2 independent practices

$\mathrm{X} 2=$ experimental group using 6 sessions: 2 sessions with supervision, 4 independent practices

$\mathrm{X} 3=$ experimental group using 6 sessions: 3 sessions with supervision, 3 independent practices

The procedures in the study are: [a] Preliminary study or pre-test was done to see the homogeneity of each class of the population. [b] The researchers gave a pre-test to see respondents' level of coping skills. [c] The researcher divided groups into three consecutive groups: X1=experimental group using 6 sessions: 4 sessions with supervision, 2 independent practice; $X 2=$ experimental group using 6 sessions: 2 sessions with supervision, 4 independent practice; X3=experimental group using 6 sessions: 3 sessions with supervision, 3 independent practice. [d] Supervision was given by the researchers and facilitators to provide comfort for the respondents. [e] Independent practice means that the respondents practicing self-help groups without supervision. [f] The researchers gave a post-test to evaluate respondents' level of coping skills.

The population in this study were all parents who cared for ASD children at the Malang City Autism Service Center. The number of ASD children at the Autism Service Center in Malang City was 47 children. The sampling technique used was purposive sampling. To minimize confounding variables, 33 parents with ASD children were chosen based on inclusion criteria: [a] children in the school age range (6 to 12 years). [b] Have taken therapy for at least 6 months. [c] Parents minimum age of 20 years. The research was located at the Malang City Autism Service Center and was conducted on March 2017.

Consent was signed after each participant had been explained about the general purpose of this study. Ethical approval was gained from the Health Polytechnic Malang, Ministry of Health of Republic of Indonesia Review Board, February 2017 (Reg.No: 386/KEPK-POLKESMA/2017). Written approval from the site was also obtained. The respondents were assessed using instrument the cognitive and psychomotor coping questionnaires pre-treatment and post-treatment. Scale used in the research was the confidence scale that the reliability coefficient alpha $(\alpha)=0.8$ so it can be said that the item is quite valid and reliable. 


\section{RESULTS AND DISCUSSION}

\subsection{Characteristics of respondents}

Table 2 is based on the age of the respondents. The average age of parents in group I was aged 40. 3 years, group II was aged 40.5 years and group III was aged 37.2 years. Meanwhile, the average age of ASD children in group I was aged 11.5 years, group II was aged 7.2 years and group III was aged 6.8 years. ASD children in group I and group III were mostly first child in the family, while in group II were mostly the second child in family structure.

Table 2. Characteristics of respondents

\begin{tabular}{lccc}
\hline \multicolumn{1}{c}{ Characteristics } & Group I & Group II & Group III \\
\hline Parents age (years) & 40.3 & 40.5 & 37.2 \\
ASD children age (years) & 11.5 & 7.2 & 6.8 \\
Birth Order & $1^{\text {st }}$ child & $2^{\text {nd }}$ child & $1^{\text {st }}$ child \\
\hline
\end{tabular}

\subsection{Parents coping strategies before and after self-help group interventions}

The purpose of this study was to analyze the effects of self-help groups on coping strategies of parents of children with ASD. Table 3 shows the difference of coping strategies among three groups before and after self-help group interventions.

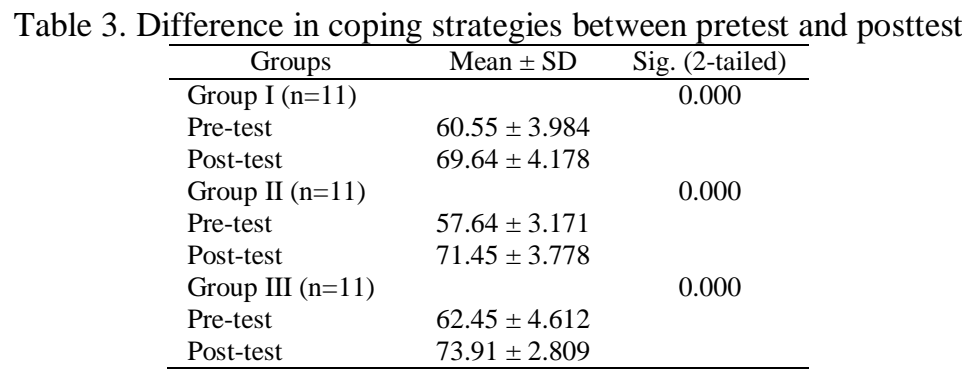

Table 3 shows the results of Paired T-test in all groups, at 5\% significance level, all null hypotheses are rejected, thus it can be concluded that there is a statistically significant difference between mean score before and after self-help group interventions. The results also showed that groups that showed significant changes were group II who received 2 times of supervision and 4 times practice independently. The group that did not show significant changes was group I who received 4 times supervision and only 2 times practice independently.

The results showed that several factors influenced coping strategies in parents with SD children, such as social support, self motivation, and the availability of facilities and infrastructure that support child care. Most parents explained that self-help groups will provide benefits to enhance their coping strategies during care giving ASD children; however each members of the group should also give mutual reinforcement so all parents feel comfortable within the groups. Parents' motivation was the main factor that influenced problem solving skills in everyday life because it was related to the initial commitment when the child was diagnosed with ASD.

Parents' motivation influence active coping skills, self-efficacy and parents' attachment. Stress could provoke the activation of coping skills through motivation and resilience. It was considered as an internal set of processes that determines a set of behaviors. Additionally, stress could activate motivation to cope with stress. People who have higher levels of motivation tend to have positive coping skills with stressful situations. Their decisions regarding type of coping skills are influenced by the expected successful coping behaviors on their stress levels and performance [13-14]. The availability of facilities and infrastructure that support the care of ASD children also affects parents coping strategies to access information and obtain health and education services which are appropriate for children with ASD.

Raising children with ASD often brings high levels of stress and strain, compared to other parents who have children with other intellectual and developmental disabilities. They have to observe and manage their ASD children from difficult behaviors, such as running away, meltdowns, sensory overload issues and consult their growth to therapists or doctors. Thus, parents will experience financial issues because of the costs of therapies, additional teachers or facilitators at school, and other activities such as childcare and 
extracurricular activities. Parents also often struggle with health services; they have to find appropriate health service providers, complete administrative paperwork to obtain subsidiary funding. These unmet service needs could exacerbate parents' stress. Complexities of ASD children behavior problems and parents as well as passive-avoidance coping could cause parents' burden. Meanwhile, the use of passive-avoidance coping had the strongest association to parents' burden. Therefore, to boost parents' self-esteem, optimism and self-efficacy while caring for ASD children, it needs support groups to promote mental well-being among parents [15-17].

The results showed a significant increase in parents' coping strategies before and after self-help group interventions. The highest difference in mean score can be seen in groups that received twice supervision. This showed that cognitive coping skills could be increased if conducted in 2 sessions. Coping strategies could be improved if each member of groups' exchanges information and knowledge about problems related to the condition of ASD children. Parents who care for children with autism will seek support, education and social policies through their participation in self-help groups. They understand that many professionals recommend parents to join self-help group as well as seek advices to professional services. Self-help groups could also promote parents' empowerment and involvement in social activities. Previous study showed that support groups could emphasize the emergence of problem-focused coping strategies to help mothers cope with situational stress in their daily life. Social support could enhance positive reinterpretation and individual growth to view something in a more positive way, and enables active coping skills. Social support given by relatives and friends, religious leaders, and health providers could be identified as coping strategies used by parents of children with special needs. It could be also identified as sources of support and active socialization. This finding is consistent with the literature as support groups serve as opportunities for information exchange, group therapy, and nonjudgmental interactions [18-20].

Self-help group was organized to enable all members of the groups to gather strength and mobilize opinion, gain opportunities for them to respond to issues concerning their livelihoods while caring for ASD children. It is an important platform to enhance parents' knowledge and awareness on ASD issues, and financial difficulties. Parents could also initiate to build generating income in several activities to help fulfilling their needs. Thus, they can contribute to the growth of the economy of families. Self-help group can come forward to form a group of the social and economic growth [21-23]. Self-help group was designed as a program that could provide assistance to the groups in both social aspects and nutritional benefits. In addition, self-help group could promote entrepreneurship using its local skills, information and assets [24-25].

Previous study investigated the benefit of self-help group that shows a short term positive effect. Self-help group of parents was based on a behavioral program and known as other therapy option for raising ASD children. This behavioral program was a therapy for parents using behavior modification techniques which were based on social learning values [26]. Self help groups provide benefits for practicing positive coping skills among parents. The benefits felt by most parents include support that was given by all members if any member encounters specific problems. Psychological stress could worsen the quality of care for children with ASD. The support provided is not only in the form of social support, but also emotional, physical and spiritual support. The self help group will gradually improve coping mechanisms of parents in caring for ASD children.

\section{CONCLUSION}

The coping strategy of parents with ASD children was influenced by parents' characteristics, social support, self-motivation and health facilities that support ASD children. Coping strategies in groups that received two supervised sessions and four times independent practice reached higher score compared to other groups. The Paired T-test results in Table 3 further concluded that there is a statistically significant difference between mean score pre-test and post-test since all null hypotheses are rejected at $5 \%$ significance level. It can be concluded that it is important to implement self-help group for parents who care for children with special needs. Self-help group could mobilize social resources for the improvement of social and economic status of each member and also create awareness about ASD issues and health services that should be adequately provided.

\section{ACKNOWLEDGEMENTS}

We would like to express our special thanks to all of the respondents for participating in this program. We also received support from Study Program of Nursing Science, Faculty of Medicine, University of Brawijaya, to conduct this research.

Effects of self-help groups intervention on coping strategies of parents of children... (Ridhoyanti Hidayah) 


\section{REFERENCES}

[1] American Psychiatric Association, Practice Guidelines for The Psychiatric Evaluation of Adults, Washington DC: American Psychiatric Association, 2016.

[2] S. R. Sharma, X. Gonda and F. I. Tarazi, "Autism Spectrum Disorder: Classification, diagnosis and therapy", Pharmacology \& Therapeutics, Vol. 190, pp. 91-104, 2018.

[3] K. Yates and A. L, "Couteur, Diagnosing autism/autism spectrum disorders", Paediatrics and Child Health, Vol. 26:12, 2016.

[4] Centers for Disease Control and Prevention, Autism Spectrum Disorder (ASD), [cited 2018 Dec 3], Available from:https://www.cdc.gov/ncbddd/autism/data.html, 2018.

[5] 2014 health profile of the population of the city of Malang (in Bahasa: Profil kesehatan penduduk kota malang tahun 2014. [cited 2018 Dec 3], Available from http: www.depkes.go.id, 2018.

[6] R. Hidayah, A. Yusuf and R. Fitryasari, "A Phenomenology Study: Coping Strategies Used By Parents Of Children With Autism Spectrum Disorder (ASD)," Masters thesis, Fakultas Keperawatan Universitas Airlangga, 2015.

[7] Y-J. Hsiaoa, K. Higgins, T. Pierce, P. J. S. Whitby and R. D. Tandy, "Parental stress, family quality of life, and family-teacher partnerships: Families of children with autism spectrum disorder," Research in Developmental Disabilities, Vol.70, pp.152-162, 2017.

[8] P. R. Benson, "Coping, distress, and well-being in mothers of children with autism," Research in Autism Spectrum Disorders, Vol.4, 217-228, 2010.

[9] L. A. Dardas and M. M. Ahmad, "For fathers raising children with autism, do coping strategies mediate or moderate the relationship between parenting stress and quality of life?," Research in Developmental Disabilities, Vol. 36, pp.620-629, 2015.

[10] L. D. Brown, X. Tang and R. L. Hollman, "The Structure of Social Exchange in Self-Help Support Groups: Development of a Measure," Am J Community Psychol. Vol. 53(0), pp. 83-95, 2014.

[11] K. Cavanagh, C. Strauss, L. Forder and F. Jones, "Can mindfulness and acceptance be learnt by self-help?: A systematic review and meta-analysis of mindfulness and acceptance-based self-help interventions," Clinical Psychology Review, Vol. 34, pp. 118-129, 2014.

[12] T. A. Nguyen, P. Oosterhoff, Y. P. Ngoc, P. Wright and A. Hardon, "Self-Help Groups Can Improve Utilization of Postnatal Care by HIV-Infected Mothers," Journal Of The Association Of Nurses In Aids Care, Vol. 20, No. 2, pp. 141-152, 2009.

[13] M-H. Li, "The Pathway Linking Stress to Active Coping: Motivation and the Trait of Resilience," Ideas and Research You Can Use: VISTAS, 2014.

[14] I. Y. S. Chan, M-Y. Leung and Q. Liang, "The Roles of Motivation and Coping Behaviours in Managing Stress: Qualitative Interview Study of Hong Kong Expatriate Construction Professionals in Mainland China," Int. J. Environ. Res. Public Health, Vol. 15, 561, 2018.

[15] J. Paynter, E. Riley, W. Beamish, M. Davies and T. Milford, "The double ABCX model of family adaptation in families of a child with an autism spectrum disorder attending an Australian early intervention service," Research in Autism Spectrum Disorders, Vol. 7, pp. 1183-1195, 2013.

[16] C. M. Shiversa, K. Krizovaa and G. K. Leeb, "Types of strain among family members of individuals with autism spectrum disorder across the lifespan,” Research in Developmental Disabilities, Vol. 68, pp. 42-51, 2017.

[17] Y. Yu, J. H. McGrew, K. L. Rand and C. E. Mosher, "Using a model of family adaptation to examine outcomes of caregivers of individuals with autism spectrum disorder transitioning into adulthood," Research in Autism Spectrum Disorders, Vol. 54, pp. 37-50, 2018.

[18] L-Y. Lin, G. I. Orsmond, W. J. Coster and E. S. Cohn, "Families of adolescents and adults with autism spectrum disorders in Taiwan: The role of social support and coping in family adaptation and maternal well-being," Research in Autism Spectrum Disorders, Vol. 5, 144-156, 2011.

[19] L-Y. Lin, "Coping strategies, caregiving burden, and depressive symptoms of Taiwanese mothers of adolescents with autism spectrum disorder," Research in Autism Spectrum Disorders, Vol. 15-16, pp. 1-9, 2015.

[20] H. R. Lutz, B. J. Patterson and J. Klein, “Coping With Autism: A Journey Toward Adaptation,” Journal of Pediatric Nursing, Vol. 27, 206-213, 2012.

[21] S. K. Basha, "An empirical study on rural women empowerment through self-help Groups and providing various earning opportunities in rural Villages in Prakasam District, Andhra Pradesh," International Journal of Scientific and Research Publications, Volume 7, Issue 7, pp. 553-566, 2017.

[22] B.C. Narasimha, P. Anand, K. S. Ravish, S. S. Navya and T. S. Ranganath, "Role of self help groups in women empowerment and health, International Journal of Community Medicine and Public Health," Narasimha BC et al. Int J Community Med Public Health, Vol. 3(8), pp. 2026-2028, 2016.

[23] A. Sahoo, "Self Help Group \& Woman Empowerment: A study on some selected SHGs," International Journal of Business and Management Invention, Volume 2 Issue 9, pp. 54-61, 2013.

[24] K. Deininger, "Economic and Social Impacts of an Innovative Self-Help Group Model in India," World Development, Vol. 43, pp. 149-163, 2013.

[25] S. Das, A. Mitra and Md. H. Ali, "A Study on the Impact of Women Self-help Groups (SHGs) on Rural Entrepreneurship Development-A Case Study in Selected Areas of West Bengal," International Journal of Scientific and Research Publications, Volume 5, Issue 3, 2015.

[26] C. Hautmann, C. Dose, K. Duda-Kirchhof, L. Greimel, M. Hellmich, S. Imort, J. Katzmann, J. Pinior and K. Scholz, "Behavioral Versus Nonbehavioral Guided Self-Help for Parents of Children With Externalizing Disorders in a Randomized Controlled Trial," Behavior Therapy, 49, 951-965, 2018. 


\section{BIOGRAPHIES OF AUTHORS}
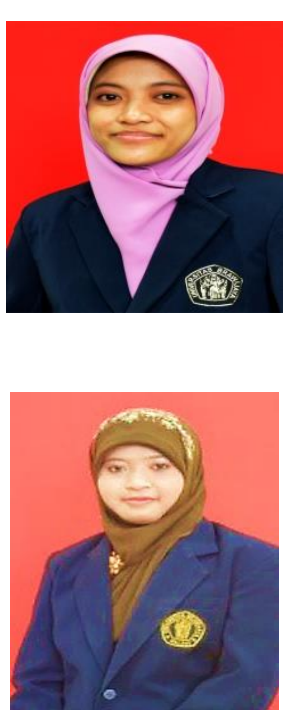

Ridhoyanti Hidayah is a lecturer in Study Program of Nursing Science, Faculty of Medicine, University of Brawijaya. Her specialty is in mental health nursing. She received her bachelor of nursing in Study Program of Nursing Science, Faculty of Medicine, University of Brawijaya. Her master of nursing was achieved from Universitas Airlangga.

She also provides mental health counselling in community integrated village in East Java.

Retno Lestari is a lecturer in Study Program of Nursing Science, Faculty of Medicine, University of Brawijaya. Her specialty is in mental health nursing. She received her bachelor of nursing in Nursing Faculty, University of Indonesia. Her master of nursing was achieved from Monash University, Australia.

She also provides mental health counseling in community integrated village in East Java. 